\title{
Attitudes toward prenatal screening and testing for Fragile $X$
}

Joanna H. Fanos, $P h D^{1,2,3}$, Kerstin A. Spangner, $M S^{4}$, and Thomas J. Musci, $M D^{2,4}$

\begin{abstract}
Purpose: Currently, the American Colleges of Medical Genetics and Obstetrics and Gynecology recommend screening in the prenatal setting only for individuals with specific family history indicators. Our aims were to study patient attitudes and psychologic impact of offering widespread screening for Fragile $\mathrm{X}$ in a prenatal setting. Methods: Participants were recruited from pregnant women referred for "Prenatal Diagnosis Options" counseling by their primary provider in the first trimester of pregnancy. Results: Pretest knowledge about Fragile X was limited; $33 \%$ had heard of Fragile $X$ syndrome before enrollment. Postcounseling knowledge was similarly limited; only 30\% accurately understood the 50\% risk for girls. Participants were strongly in favor of being tested or screened, and did not experience undue anxiety related to Fragile $X$ testing. Respondents hoped that knowledge of Fragile $X$ in the general population would increase, and recommended that screening be offered during routine prenatal care. Conclusion: Fragile $X$ screening in this setting was a favorable testing experience for the participants. Limited pretest knowledge and posttest retention of specific genetic information on Fragile $X$ suggest that widespread screening will pose significant counseling and educational challenges, which should be addressed in such programs. Genet Med 2006:8(2):129-133.
\end{abstract}

Key Words: Fragile $X$, genetic counseling, genetic testing, prenatal testing, prenatal screening

Fragile $\mathrm{X}$ syndrome is the most common cause of inherited mental retardation, seen in approximately 1 in 4000 males and 1 in 4000 to 8000 females. ${ }^{1}$ The majority of males exhibit characteristic physical features and significant intellectual disability and behavioral problems, and are unable to live independently. ${ }^{2,3}$ Affected females exhibit a similar but usually less severe phenotype. ${ }^{4}$ Currently, the American College of Medical Genetics ${ }^{5}$ and the American College of Obstetricians and Gynecologists ${ }^{6}$ recommend screening patients in the prenatal setting only if they have specific family history indicators, for example, Fragile X syndrome or mental retardation of undiagnosed cause, or testing the fetus of a known carrier mother. There is concern that effective means may not be in place to provide pretest education and to inform tested populations of the meaning and implications of results.

Although the exact carrier frequency in a low-risk population is not known with certainty, a reasonable estimate based on a compilation of studies is that 1 in 300 women is a carrier of the FMR1 premutation (60 to 200 CGG triplet repeats). ${ }^{7,8}$ Prenatal screening would enable identification of both carriers of premutations and those women who are unaffected full muta-

\footnotetext{
From the ${ }^{1}$ Department of Pediatrics, Dartmouth Medical School, Lebanon, New Hampshire; ${ }^{2}$ Research Institute; ${ }^{3}$ Department of Pediatrics; and ${ }^{4}$ Prenatal Diagnosis Center, California Pacific Medical Center, San Francisco, California.

Joanna H. Fanos, PhD, Department of Pediatrics, Dartmouth Medical School, One Medical Center Drive, Lebanon, NH 03756.

Submitted for publication August 3, 2005.

Accepted for publication November 18, 2005.
}

DOI: 10.1097/01.gim.0000200158.66554.7f tion carriers. Because the likelihood of premutation expansion across the range of premutation sizes is approximately $16 \%,{ }^{7}$ carrier females appropriately might choose to undergo invasive fetal testing for definitive diagnosis, particularly in the case of male fetuses.

Documented difficulties for affected families struggling with other genetic disorders in understanding and retaining medical and genetic information raise concerns. ${ }^{9-12}$ There have been no prospective studies to evaluate the practicalities of initiating widespread Fragile X screening. Our goal was to undertake a first-phase study in prenatal carrier screening for Fragile X to understand patients' attitudes and the psychologic impact of screening low-risk women, and to assess posttest retention of genetic and medical knowledge. We offered Fragile $\mathrm{X}$ testing to two cohorts of consenting patients, both with $(N=10)$ and without $(N=10)$ a specific family history that would otherwise warrant screening.

\section{MATERIALS AND METHODS}

Patients were referred to the California Pacific Medical Center Prenatal Diagnosis Center for advanced maternal age. During recruitment, all patients presenting for routine genetic counseling by the research genetic counselor (K.S.), and who had no family history indicators that would otherwise trigger the offering of Fragile X, were given a flyer describing Fragile X and participation in the study. During this same period a "family history" group was given the same flyer when the women presented for genetic counseling and were invited to participate in the study. The family history group included patients 
who would otherwise be offered Fragile $\mathrm{X}$ screening on the basis of their family history or risk factors such as mental retardation or autism that would fit an X-linked inheritance pattern. All patients were seen for a 45-minute genetic counseling session with discussion of prenatal diagnostic and screening options (e.g., chorionic villus sampling, amniocentesis, nuchal translucency, and maternal serum screening); in addition, a detailed genetic family history was obtained and a pedigree was drawn. For all patients who agreed to the study, a 10-minute discussion of Fragile $\mathrm{X}$ and its inheritance followed. The institutional review board-approved consent forms were then reviewed and signed. The one-time blood draw was performed at the conclusion of the initial genetic counseling session and sent for analysis to Genzyme Genetics (Westborough, MA).

After the results were received, 20 participants were interviewed (10 with family history, 10 without). The first 12 participants (6 in each group) were interviewed in depth over the phone by Dr. Fanos for approximately 1 hour and read questions concerning their knowledge and attitudes toward testing for Fragile X. The next eight participants (four in each group) were asked the same questions by the research genetic counselor for approximately $1 / 2$ hour. The study was approved by the California Pacific Medical Center Institutional Review Board, and informed consent was obtained from all participants by the genetic counselor during the initial genetic counseling session.

Twenty women were interviewed. Participants ranged in age from 26 to 41 years $(M=35)$. All but two were married (two were single). Median education was a college degree; median household income was $\$ 150,000$. Of the participants, 13 were white, two were Latina, three were Asian, and two were AfroAmerican. Ten women already had one or more children. Of those 10 participants who had a family history of Fragile X, mental retardation, or autism, two had a brother with mental retardation, two had a maternal or paternal uncle with mental retardation, two had a maternal cousin once removed with developmental delay, two had sons with speech delay, one had a son with autism, and one had a son with Fragile X.

Twelve individuals were interviewed over the phone for approximately 1 hour. Interviews were conducted by J.H.F., taperecorded, and transcribed verbatim. On the basis of the interview material, rating scales were developed by J.H.F. on several categories capturing important aspects of psychosocial adaptation. Three interviews were selected at random from the sample and given to an outside rater. When a suitable level of reliability had been attained (kappa $>0.90$ ), the remaining interviews were rated by the outside rater. Interrater reliability was obtained on coded scales and yielded an overall kappa of 1.0 .

\section{RESULTS}

\section{Medical knowledge of Fragile $X$ and attitudes toward prenatal testing}

On the basis of the questionnaire administered in the posttest period, after participants had received results, the majority retained basic information about the genetics of Fragile X ( $\mathrm{Ta}$ ble 1). Most recalled the $50 \%$ carrier risk for each boy of carrier mothers (13/20), whereas 5 of 20 underestimated the risk at $25 \%$. One participant believed it was $100 \%$. Fewer participants knew the $50 \%$ risk for girls (five believed it was $25 \%$, and seven believed it was $0 \%)$. Sixteen participants correctly answered the mother is the carrier in the case of a Fragile X-affected child; one thought the father would be the carrier, and two thought both parents must be carriers.

The majority of participants were clearly interested in fetal testing for Fragile $\mathrm{X}$ if testing indicated carrier status (16/20). When the participants were asked whether they would consider terminating the pregnancy if a male fetus were determined to have Fragile X, 12 said they would, two with a family history said no, and six did not know, equally divided between the two groups. However, only three believed they would consider terminating a pregnancy if a female fetus inherited the mutation, seven said no, and half (10) did not know what they would do. Most needed more information to understand how that condition would actually affect their child's life. For individuals with a family history, two considerations were influential in their decision. First, their relative's situation elicited sad feelings. One woman found her uncle's situation heartbreaking, because he is "close to normal but doesn't fit in with normal people, so he's really caught in this in-between world." The second consideration was based on their having witnessed the attendant responsibilities firsthand: They worried what would happen when they got older and were not able to care for their child.

\section{Testing experience}

The decision of whether to be tested for Fragile $\mathrm{X}$ in this context seemed not to be difficult for our participants. Twothirds of our interviewees had not heard of the condition; only one with a family history of related disorders had heard of Fragile X. Those with no family history believed that it was not an invasive test, involving a simple blood draw, and believed that knowledge is power. One woman recalled the counselor comparing Fragile X with autism, and because she had had some personal experience with that condition, she considered it a significant reason for screening. For those with a family history, the offer of testing triggered thoughts of their affected relative. They considered a potential positive finding a "pretty severe result," and wanted time to prepare for what may come. One woman, with no family history, decided that from now on she would have testing for all her pregnancies, not understanding that this would not be necessary.

In the several weeks after testing while they waited for results, there was little anxiety expressed by our sample. Those with a family history were not unduly distressed (no one was rated as having moderate or severe anxiety). One woman whose paternal uncle had mental retardation was calm because her father exhibited no symptoms, not understanding that this was an incorrect assumption. A mother of a child with autism believed that much of his problems stemmed from his having been deprived of oxygen at birth, "so it was a physical condi- 
Table 1

Medical and genetics knowledge of Fragile X

\begin{tabular}{|c|c|c|c|c|}
\hline Question & Correct responses & $\begin{array}{c}\text { Correct } \\
(\%)\end{array}$ & $\begin{array}{l}\text { Not correct } \\
\quad(\%)\end{array}$ & $\begin{array}{l}\text { Do not know } \\
(\%)\end{array}$ \\
\hline 1. Fragile $\mathrm{X}$ is a curable disorder & No & 95 & 0 & 5 \\
\hline With family history & & 90 & 0 & 10 \\
\hline Without family history & & 100 & 0 & 0 \\
\hline 2. Most boys with Fragile $\mathrm{X}$ have learning difficulties & Yes & 90 & 5 & 5 \\
\hline With family history & & 80 & 10 & 10 \\
\hline Without family history & & 100 & 0 & 0 \\
\hline 3. Most boys with Fragile X have behavioral problems & Yes & 60 & 5 & 35 \\
\hline With family history & & 50 & 10 & 40 \\
\hline Without family history & & 70 & 0 & 30 \\
\hline 4. Most boys with Fragile $\mathrm{X}$ have characteristic facial features & Yes & 35 & 30 & 35 \\
\hline With family history & & 30 & 30 & 40 \\
\hline Without family history & & 40 & 30 & 30 \\
\hline $\begin{array}{l}\text { 5. Does having no known family history of mental retardation mean a person } \\
\text { cannot carry a Fragile X mutation? }\end{array}$ & No & 85 & 5 & 10 \\
\hline With family history & & 80 & 0 & 20 \\
\hline Without family history & & 90 & 10 & 0 \\
\hline 6. Are there any interventions for a child with Fragile X that would be helpful? & Yes & 40 & 30 & 30 \\
\hline With family history & & 50 & 20 & 30 \\
\hline Without family history & & 30 & 40 & 30 \\
\hline 7. Has the gene that is defective in Fragile $\mathrm{X}$ been identified? & Yes & 75 & 5 & 20 \\
\hline With family history & & 60 & 10 & 30 \\
\hline Without family history & & 90 & 0 & 10 \\
\hline $\begin{array}{l}\text { 8. If a mother carries a mutation for Fragile } \mathrm{X} \text {, what are the chances for each } \\
\text { male child that he will have Fragile } \mathrm{X} \text { ? }\end{array}$ & $50 \%$ & 65 & 30 & 5 \\
\hline With family history & & 60 & 30 & 10 \\
\hline Without family history & & 70 & 30 & 0 \\
\hline $\begin{array}{l}\text { 9. If a mother carries a mutation for Fragile } X \text {, what are the chances for each } \\
\text { female child that she will have Fragile X? }\end{array}$ & $50 \%$ & 30 & 60 & 10 \\
\hline With family history & & 40 & 50 & 10 \\
\hline Without family history & & 20 & 70 & 10 \\
\hline 10. Compared with Fragile $\mathrm{X}$ in boys, Fragile $\mathrm{X}$ syndrome in girls is & Less severe & 60 & 30 & 10 \\
\hline With family history & & 50 & 40 & 10 \\
\hline Without family history & & 70 & 20 & 10 \\
\hline 11. If there is a boy with Fragile $\mathrm{X}$, which one of the following is true? & The mother is usually the carrier & 80 & 15 & 5 \\
\hline With family history & & 90 & 0 & 10 \\
\hline Without family history & & 70 & 30 & 0 \\
\hline 12. Do you know if prenatal testing for a fetus is available to diagnose Fragile $\mathrm{X}$ ? & Yes & 75 & 15 & 10 \\
\hline With family history & & 90 & 10 & 0 \\
\hline Without family history & & 60 & 20 & 20 \\
\hline 13. Are there significant risks associated with testing your fetus? & Yes & 40 & 55 & 5 \\
\hline With family history & & 20 & 70 & 10 \\
\hline Without family history & & 60 & 40 & $\begin{array}{c}0 \\
\text { (continued) }\end{array}$ \\
\hline
\end{tabular}


Table 1

Continued

\begin{tabular}{|c|c|c|c|c|}
\hline Question & Correct responses & $\begin{array}{c}\text { Correct } \\
(\%)\end{array}$ & $\begin{array}{c}\text { Not correct } \\
(\%)\end{array}$ & $\begin{array}{c}\text { Do not know } \\
(\%)\end{array}$ \\
\hline 14. What is the risk of a miscarriage because of the procedure (amniocentesis)? & $1: 300$ & 85 & 10 & 5 \\
\hline With family history & & 80 & 10 & 10 \\
\hline Without family history & & 90 & 10 & 0 \\
\hline 15. Is prenatal testing highly accurate? & Yes & 95 & 0 & 5 \\
\hline With family history & & 90 & 0 & 10 \\
\hline Without family history & & 100 & 0 & 0 \\
\hline
\end{tabular}

tion as opposed to a genetic one." Of those with no family history, most were not distressed waiting for results; two were rated as having moderate anxiety. For one individual, worries of Fragile X results were dwarfed by concerns over the findings of an amniocentesis performed for fetal karyotype analysis. One woman was confident that her next child would be unaffected because she already had a healthy child. However, for one participant, screening raised concerns for her spouse after she received good news from the counselor: "It was only after I came and told my husband the news that he said, 'Well, is that it? Could I be a carrier?' And I thought, I don't know the answer to that." Not wanting to bother the counselor, she decided to wait for clarification until she received a call with other results, and was waiting with some apprehension. One other woman, technically with no family history, although her brother's son had autism, was relieved to learn she was not a carrier: "I'm lousy at politics and social skills, and I told my husband since I met him, I think I'm a little bit mentally retarded, a little autistic."

\section{Attitudes concerning population screening for Fragile $\mathbf{X}$}

Participants were overwhelmingly in favor of screening for Fragile X. Several stated that they felt fortunate that they were aged more than 35 years and thus had sought genetic counseling, because their obstetrician/gynecologist had not suggested the test. They appreciated having received the information in the package before the appointment, so they had time to read the material and discuss the option with their husbands. One woman resented that the health care provider currently is the one who decides which tests will be offered rather than the individual. Most explained that even if they knew they would not terminate a fetus, they would want the information so they could prepare themselves. When asked about the potential for increased anxiety for women, several pointed out that during pregnancy anxiety is raised anyway because of hormonal changes and facing other tests such as amniocentesis. As one woman suggested: "Maybe the population needs to be more educated about all these disorders that when they go to have a test that it's not a big shock: 'Oh my God, why do they think I need to be tested?"”

\section{Developmental issues}

Our sample had experienced various adverse events in their childhood. Of those with a family history, one woman's father had a "terrifying" illness when she was 11 years old; one had a younger sister who was jaundiced at birth and remained hospitalized for some time; one had a mentally retarded brother; and one had an autistic brother. Of those interviewees who had no family history, $50 \%$ were children of divorce, one had experienced the traumatic death of a grandmother, and several had undergone traumatic exile situations. When asked about their sense of self as anxious or not, most described themselves as fairly anxious and needing control. It is possible that their proclivity for control as an expression of not wanting to be surprised by an unfortunate event was related to their desire for testing. At times, early coping strategies seemed to influence hypothetic decisions about termination, as can be seen in the following case example.

Allison was born in Vietnam during the war. Her father, a physician, was imprisoned in a concentration camp for several years. After his release, the family escaped by boat, a terrifying experience for Allison, then a child, who witnessed the drowning of one of her siblings. Allison felt that she has been through more than most young people, but also knew that her religious beliefs have given her strength to face life obstacles. At the time of the interview, she was awaiting results of her chorionic villus sampling and struggling with her decision if results were positive for Down syndrome. Convinced that she would not be a good mother to a retarded baby, she stated “. . .99.9\% I think my emotional side will decide; logically, I don't think it's a good choice, but I've been through a lot in my own life, and God sees me through.”

\section{DISCUSSION}

We undertook this small study to learn about the attitudes of patients offered prenatal Fragile X carrier screening, especially those with no family history or risk factors. We were also interested in understanding how much Fragile X-specific information would be retained by patients in the context of a comprehensive "routine" prenatal genetic counseling session. We included a group of women who would generally trigger the offering of Fragile $\mathrm{X}$ carrier screening per the recommendations of the American College of Obstetricians and Gynecologists and the American College of Medical Genetics as a comparison. 
Individuals in our sample were optimistic about prenatal testing, similar to the findings of McConkie-Rosell et al., ${ }^{13}$ in which respondents viewed Fragile $\mathrm{X}$ as a very serious condition with potential profound consequences for their offspring. In our sample, in which there was only one obligate carrier, eagerness to be tested may relate more to the personality characteristics of those seeking genetic counseling or those characteristics of individuals agreeing to participate in a research study.

Participants seemed unaware of the potential risks of having an offspring with Fragile X, which was consistent with their general lack of knowledge of the condition before screening. This is often not the case with individuals in families who are at high risk of passing on genetic disorders to their offspring. ${ }^{11}$ Respondents in our sample, both with and without a family history, seemed unsophisticated in their thinking through the complexities of social and psychologic issues as they relate to Fragile X screening.

Individuals, both with and without a family history (with one exception) were equally nonplussed while awaiting results. It may be that because the relative had not been diagnosed with Fragile X, but rather had a family history of developmental delay or autism, the connection of these conditions with Fragile $\mathrm{X}$ did not trigger an anxiety response. As the relationship between Fragile X and these other developmental abnormalities becomes better known in the general public, there may be increased anxiety associated with screening.

Retention of medical and genetic elementary knowledge about Fragile X syndrome was limited. This was noted despite the fact that each participant had one-on-one counseling with an experienced genetic counselor and that the group in general was highly educated. Although there were no statistically significant differences in accuracy of medical knowledge between the two groups, those with a family history were more likely to underestimate the significant risks of testing the fetus. This may be because of their balancing perceived risks with the significant potential of having an affected child, whereas those with no family history would be less eager to risk an invasive medical test. Those with a family history that would currently trigger the offering of testing were slightly less knowledgeable about the features and genetics of Fragile X. It should be noted, however, that all but one of the "family history" group had no intimate experience with Fragile X, and thus knowledge about the syndrome might not differ from that of the general population. That they seemed slightly less knowledgeable was most likely related to sampling error. It is, however, interesting that such a high proportion in each group had never heard of Fragile $\mathrm{X}$ despite the frequency of the disorder and the high level of education of participants.

Pretest counseling and patient education remain an important concern for the introduction of any new genetic test into the screening menu in the prenatal setting. Although we made every attempt in counseling to educate patients about Fragile
$\mathrm{X}$, women were there primarily for genetic counseling for prenatal testing options, not Fragile X screening. It is possible that some of our patients experienced "information overload" because in each session Fragile $\mathrm{X}$ was discussed last. This raises a central concern regarding the effectiveness of counseling as the number of options or genetic conditions discussed increases. Although it may be feasible for the genetic counselor or medical provider to give patients sufficient information, the patients may not be in a position to receive complex details about a wide variety of possible disorders. We envision that widespread Fragile X carrier screening may be incorporated into a standard array of offerings by the primary obstetrical provider. As more prenatal diagnosis centers begin the widespread offering of screening, ${ }^{8}$ and as screening is viewed more favorably from a cost-effectiveness perspective, ${ }^{7}$ it will be important to develop appropriate educational tools that will allow for adequate informed consent.

\section{ACKNOWLEDGMENTS}

We are grateful to Gabriella Hegwer, MS, for providing some of the participants, to Amy Cronister, MS, Genzyme Genetics, for helpful discussions before the study, and to Noushin Khayyami for rating interviews. We thank the women who participated in this research; their names have been changed to preserve confidentiality. This research was supported by California Pacific Medical Center Foundation (Wishes for Wellness) and Genzyme Genetics, Inc.

\section{References}

1. Pembrey ME, Barnicoat AJ, Carmichael B, Bobrow M, et al. An assessment of screening strategies for fragile X syndrome in the UK. Health Technol Assess 2001;5:1-95.

2. Hagerman RJ, Hagerman PJ. Fragile X syndrome: diagnosis, treatment, and research, 3rd ed. Baltimore: Johns Hopkins University Press; 2002.

3. Cornish K, Sudhalter V, Turk J . Attention and language in fragile X. Ment Retard Dev Disabil Res Rev 2004;10(1):11-16.

4. Loesch DZ, Huggins RM, Bui QM, Taylor AK, et al. Relationship of deficits of FMR1 gene specific protein with physical phenotype of fragile $\mathrm{X}$ males and females in pedigrees: a new perspective. Am J Med Genet A 2003;118(2):127-134.

5. American College of Medical Genetics. Fragile X syndrome: diagnostic and carrier testing. Working Group of the Genetic Screening Subcommittee of the Clinical Practice Committee. Am J Med Genet 1994;53(4):380-381.

6. American College of Obstetricians and Gynecologists Committee on Genetics. ACOG committee opinion. Fragile X syndrome. Int J Gynaecol Obstet 1996;52(2): 209-210.

7. Musci TJ, Caughey AB. Cost-effectiveness analysis of prenatal population-based fragile X carrier screening. Am J Obstet Gynecol 2005;192(6):1905-1912.

8. Cronister A, DiMaio M, Mahoney M, Donnenfeld AE, et al. Fragile X syndrome carrier screening in the prenatal genetic testing setting. Genet Med 2005;7(4):246-250.

9. Fanos JH, Johnson JP. Perception of carrier status by cystic fibrosis siblings. Am J Hum Genet 1995;57(2):431-438.

10. Fanos JH, Gatti RA. A mark on the arm: myths of carrier status in sibs of individuals with ataxia-telangiectasia. Am J Med Genet 1999;86(4):338-346.

11. Fanos JH, Davis J, Puck JM. Sib understanding of genetics and attitudes toward carrier testing for X-linked severe combined immunodeficiency. Am J Med Genet 2001;98:46-56.

12. Fanos JH, Strange C. "The lion, the witch and the wardrobe": impact on sibs of individuals with AAT deficiency. Am J Med Genet A 2004;130(3):251-257.

13. McConkie-Rosell A, Spiridigliozzi GA, Iafolla T, Tartleton J, et al. Carrier testing in the fragile X syndrome: attitudes and opinions of obligate carriers. Am J Med Genet 1997;68:62-69. 